\title{
SALUTE TO JÁNOS KORNAI
}

\author{
Eric MASKIN
}

I am delighted to introduce this special issue and to salute János Kornai on the occasion of his ninetieth birthday. I congratulate him on my own behalf and that of the Harvard Economics Department, where he was my colleague and friend for many years.

I don't think it is any exaggeration to say that János is the world's leading economic scholar of centrally planned economies and of comparisons with marketoriented economies. It was largely because of his stature in this field that Harvard invited him to join the faculty in the mid-1980s. The timing was fortuitous - only a half-decade later, the former Soviet-bloc countries of Eastern Europe started on their path towards capitalism, and János's ideas had a major influence on the discussion surrounding this transition.

Having János as a colleague was sheer intellectual fun. Soon after he arrived, he and I started meeting occasionally to talk about how some of his ideas - particularly the concept of a "soft budget constraint" - might be formulated in the framework of modern economic theory, and thereby be made more accessible to economists unfamiliar with the literature on socialism.

Later, when he was invited to give the Tanner Lectures at Stanford and I was to be his discussant, we met for long and frequent sessions to assess and debate

Eric Maskin, Professor at Harvard University and Higher School of Economics, Moscow; Nobel Laureate (2007). E-mail: emaskin@fas.harvard.edu 
nearly every word in his text, "Market Socialism Revisited." That was an especially exhilarating experience.

But I think that the most important "collaboration" between János and me at Harvard was our joint supervision of several extraordinary PhD students from China. These students were deeply committed to understanding the unique trajectory of the Chinese economy since Deng Xiaoping's reforms of the late 1970s. They relied on János for his unsurpassed expertise on the workings of state-run economic systems and on me for the tools of economic theory. Perhaps one measure of our success as supervisors is that a number of our former students are now highly influential thinkers in the Chinese academic and policy worlds.

Initially, I didn’t get deeply involved with János's ideas except to serve as a sounding board and critic for his thinking. But eventually I came to find one particular idea - the soft budget constraint - so powerful that I ended up making a considerable research investment in it myself. Roughly speaking, a soft budget constraint holds wherever an enterprise's funding source - say, a bank or a government - cannot commit itself to keep the enterprise to a fixed budget. János showed that centralized economies are more prone to soft budget constraints than are their decentralized counterparts. This inspired Mathias Dewatripont and me to explore the mechanism by which decentralization of credit can "harden" budget constraints and make credit markets more efficient. Some years later, I teamed up with János himself and with Gérard Roland for a broad analysis and review of soft budget constraints in their many guises: in the corporate world, in banking, and even at the national level.

I very much missed János and his wife, Zsuzsa, when they left Harvard in 2002 and moved back to Budapest permanently, although we continued to correspond by email. Fortunately, there were two golden opportunities to renew our friendship. The first was when the Kornais came to Princeton in the spring of 2007 (I was then on the faculty of the Institute for Advanced Study). The second was when my wife and I visited Budapest in the fall of 2008. Still, those two occasions now seem a long time ago. And, I must confess that a major reason I am looking forward so much to János's 90th birthday is not just the chance to honor an intellectual giant, but to have a good excuse to come to Hungary and see János and Zsuzsa in person again. 